Rotimi, J. O. B., Wilkinson, S. (2014) "Improving environmental management legislation to facilitate postdisaster reconstruction", International Journal of Disaster Resilience in the Built Environment, Vol. 5 Issue 1.

http://www.emeraldinsight.com/journals.htm?articleid=17105628\&show=abstract

\title{
Improving environmental management legislation to facilitate post-disaster reconstruction
}

James Olabode Bamidele Rotimi, Suzanne Wilkinson

International Journal of Disaster Resilience in the Built Environment, Vol. 5 Issue 1.

\begin{abstract}
Purpose

The study explores improvements to environmental management legislation that will enable the implementation of post disaster reconstruction activities after the built environment has been affected by a natural disaster.
\end{abstract}

\section{Design}

The study programme collates opinions from building and development control officers and other disaster practitioners based in New Zealand. The objective was to determine the practical implication of implementing reconstruction arrangements under the RMA. The survey was administered online, and a data set of 80 responses was used for the analyses.

\section{Findings}

The survey results show that current reconstruction framework in New Zealand may cause procedural constraints and become burdensome to property owners who desire early recovery from a disaster event. Therefore improvements are suggested to certain aspects of the RMA reconstruction provisions, so that it facilitates early recovery from natural disasters.

\section{Originality/value}

The paper is one aspect of a doctoral study that reviewed the implications of implementing reconstruction under existing legislative framework. It highlights the need for improvements to environmental management legislation to enable effective reconstruction after natural disasters in New Zealand. These have wider implications to other countries to revise their legislation before any disaster, thus reducing the problems that may be experienced while implementing environmental and developmental legislation.

Keywords: Resource Management Act, Post-Disaster Reconstruction, New Zealand 


\section{Introduction}

The scale and magnitude of natural disasters are a source of concern. For example in 2010, there were 373 natural disasters, about 316,000 recorded deaths and economic damages worth over US\$ 100 billion (EM-DAT,2011). Though the trend line showed a drop in natural disasters compared to 2009 figures, there is an unexpected increase in future vulnerabilities. This could be due to factors such as global climate change, urbanisation and rise in world population. In New Zealand and Pacific island countries, the scale of destruction from natural disasters is on the increase. Recently Christchurch, New Zealand was devastated by two major earthquakes in September 2010 and February 2011. These earthquakes resulted in over 140 deaths and about 10,000 buildings which will need to be rebuilt or demolished.

What these disaster trends mean is that disaster management activities should focus on reducing the impact of natural events on communities at every level of intervention. Vulnerable countries will need to prepare across the four realms of disaster management i.e. reduction, readiness, response and recovery. Preparing in advance helps to alleviate the scale of devastation and destruction that follows large catastrophes and very often allows recovery from the events to be accelerated (Ye, 2002). A community with good disaster management system buffers the effect of natural disasters. This paper addresses the question: what improvements can be made to existing environmental management legislation so that it enables effective reconstruction following a natural hazard event? The paper is based on research from New Zealand, but as will be explained in later sections, it could also have wider implications for improving disasterrelated legislation in other vulnerable countries.

\section{Literature Review}

As explained previously, pre-planning becomes a necessity if disaster management activities are to be successfully implemented (Cousins, 2004). Policies and procedural arrangements would need to be constituted for disaster management (Comerio, 2004), knowing that the recovery needs of different stakeholders are often difficult to achieve because the organisation and coordination of recovery is complex (Chan et l., 2006; Kouzmin, Jarman, \& Rosenthal, 1995; Mitchell, 2006; Schneider, 1995; W. Smith \& Dowell, 2000). Recovery policies have to be underpinned by enabling legislation especially, where special powers, rights or responsibilities need to be defined for different agencies involved in recovery efforts (ACTIONAID Nepal, 2004). Spence (2004) explains that an enabling legislation would provide the environment suitable for the interaction and interrelationship of disaster management stakeholders.

This paper approaches effective and efficient implementation of post-disaster reconstruction from the viewpoint of legislation and regulations; believing that legislation and regulatory provisions significantly influence the organisation for long-term recovery after natural disasters. The authors believe that without a developed framework, reconstruction and re-development programmes may be carried out on an ad-hoc basis and with little regard for community needs. Thus this paper appraises a key piece of legislation that has direct impact on the reconstruction of physical assets in New Zealand, the Resource Management Act (RMA) 1991.

The RMA encapsulates environmental management legislation in New Zealand. It is the Act that promotes the sustainable management of land, sea, air and water, so that New Zealand resources are protected for future generations (Skelton \& Memon, 2002). The Act provides for the avoidance, remedy or mitigation of the adverse effects of proposed activities on the environment; 
and also ensures that environmental principles are provided for in every resource management planning and decision-making activities. The New Zealand's Ministry for Environment (MfE) provides oversight coordination of the RMA through local councils, to ensure that the Act is interpreted in line with respective regional policy statement and district plans.

When damaged physical properties are to be built, they may require resource consents under the RMA, for which an application is made as in normal developmental projects. What will be peculiar to post disaster reconstruction projects is the urgency to reach a decision on the consent applications to facilitate community recovery. However evidence suggests that environmental legislation could become impediments to the realisation of reconstruction objectives. The impediments may occur as a result of procedural constraints inherent in development legislation (Meese, Butler \& Holmes, 2005); and consequently these become sources of disaster vulnerability (Gavidia \& Crivellari, 2006). For example, Feast (1995) commented that much of New Zealand's development legislation (including the RMA) may not be operable during disaster recovery. Feast showed that the requirements for wide public consultations before certain developments can be approved under the RMA, may be precluded by the problems of meeting the reconstruction requirements of a devastated city within a reasonable period (Feast, 1995). Till now the RMA consenting process remains slow and costly and will need to be amended to stimulate the general economy (N. Smith, 2009).

The authors believe that under the current procedural arrangements in the RMA, disaster recovery may become endless and community expectations unfulfilled. Thus there has to be deliberate and sustained approaches towards post disaster management that will build upon well grounded policies and strategic frameworks (Coghlan, 2004; Comerio, 2004; E. L. Quarantelli, 2006). This may require modifying normal construction processes to allow for reconstruction to take place, especially where a sustained programme is involved.

\subsection{New Zealand's vulnerability to Disaster and its Environmental Policies}

New Zealand is exposed to no less than 17 significant hazards varying from natural and technological to man-made hazards (ODESC, 2007). The list of hazards include: earthquakes, volcanoes, landslides, tsunamis, coastal hazards, floods, severe winds, snow, droughts, wildfires, animals and plant pests and diseases, infectious human disease pandemics, infrastructure failures, hazardous substance incidents, major transportation accidents, terrorism and food safety. The country is highly disposed to natural disasters which are attested to by the frequency of declared state of emergencies. The county has a high disposition to rainfall related hazards (floods and landslips) which have been largely confined to rural areas and are of low-magnitude. Disasters with wide scale physical and societal dislocations have been few and far between, However two recent earthquakes in late 2010 and early 2011 are evidence of the real risks that New Zealand communities are faced with and show the importance of implementing disaster risk management strategies.

It is important that appropriate legislation and regulatory requirements are put in place beforehand to assist with post-disaster reconstruction efforts. The overall desire is for legislation to enhance the recovery and reconstruction process so that the community (presents opportunities) recovers rapidly while also reducing future disaster risks. Opportunities for increased resiliency do not remain for too long after disasters (cousins, 2004). The desire to return to normalcy builds quickly after disasters and with a good flow of external resources, the opportunities to introduce mitigating measures may become limited over time (Berke \& 
Campanella, 2006). Menoni (2001) notes that sometimes market forces put pressures to reconstruct as quickly thereby hampering efforts to implement lessons learnt from a disaster.

Pressures to rebuild key lifelines are borne by national and local administration with the implication of reduced quality of delivery. This sort of approach has led to increased vulnerability because of poorly planned and designed built environment that could withstand future disasters (Jigyasu, 2004; Shaw et al., 2003). For example buildings reconstructed in the same vulnerable locations create increased and additional risks (Wamsler, 2004). The clamour to rebuild quickly also amplifies the social, economic and environmental weaknesses that result in large-scale disasters (Ingram et al., 2006). Extra quality and embedded forethought can help reconstructed built assets and community to be resilient, but there is inevitably a trade-off between time, cost and quality, which recovering communities would have to make at all times (Olshansky, 2005).

Within the context of past experiences in New Zealand, there is an imperative to have revised systems in place before a larger scale disaster occurs. Larger scale disasters present different set of challenges beyond which New Zealand's response organisations are familiar with. Preplanning for reconstruction should therefore prevent any disaster event becoming protracted. In the words of a former Chairman of the Earthquake Commission, Neville Young, 'natural disasters are by definition unpredictable and it is much more difficult to plan response under the stress of post-disaster trauma than in the calm before the storm' (Earthquake Commission, 2005).

\subsection{Environmental Management Legislation in New Zealand}

Legislation provides the legal sanction on disaster policies and action plans 9ACTIONAID Nepal, 2004) especially as they will need to be integrated with other national or local development planning policies by respective government hierarchies. Environmental management legislation in New Zealand is encapsulated in the RMA.

The larger study from which this paper was culled out had envisaged impediments during the implementation of the RMA in a significant reconstruction programme in New Zealand. These impediments are presented under the following sub-headings.

\subsubsection{Issues associated with bureaucracy and procedural requirements}

Application for a permit (resource planning consent) is required to be submitted before any proposed physical (re)developments projects could proceed (s9-s23). Approval for such permits is granted by the councils (referred to as the Consent Authority in s30, s31) with consultation and agreement with the respective local community. This consent application process provides for an assessment of any likely environmental impacts of the proposals and how these would be mitigated. The potential effects of any development proposal on the environment (whether minor or major) will determine whether the resource consent application should be publicly notified, require limited notification or non-notified (s93-s95). This requirement for public notification influences the processing time for resource consents. For example, the maximum time allowed for a non-notified consent decision to be reached is 20 working days from the date of lodgement of an application, while a notified consent decision will take a maximum of 50 working days or 70 working days if a public hearing is necessary. Times for processing resource consents are indicative only; as the times may be extended in situations when higher than normal volumes of consent processing are encountered (Ministry for Environment, 2006). 
A two-yearly survey conducted by the Ministry for Environment on local authorities gives context to the problems that may be experienced during the RMA consent process. A 2007-08 survey found that only $69 \%$ of consents were processed within the statutory time limits (Ministry for Environment, 2009). This figure is lower than the 73\% realised in 2005-06 survey period (Ministry for Environment, 2008). Some underlying issues pertaining these results were unmasked in an IPENZ position paper on the RMA (IPENZ, 2008). For example, IPENZ (2008) believes there is a need to address the non-compliant cases (31\% which could not be processed within the statutory time) within reasonable timeframes to avoid a spike of workload on the consenting authorities. There is little doubt that consent applications would overwhelm local councils' capacities during post-disaster recovery. It is likely that there would be a spike in number of applications above normal, adding to the existing 31\% backlog of unattended applications. The delayed processing could lead to unnecessary cost burdens to applicants, since development projects will have to be put on hold till approval is granted. Problems with RMA consenting delays have always been protracted and are not empty of resentments in New Zealand (Mcshane, 2003; Page, 2005).

\subsubsection{Emergency Work Prioritisation Issues}

The RMA caters for redevelopment works that may be required under situations of urgency. Section 330 of the Act deals with works considered emergency which may have resulted from a disaster event. This is the key section that gives powers to a person or entity to undertake emergency works or to take preventative or remedial action without necessarily obtaining resource consents when one would normally have been required (Harper, 2006). Similarly the section gives backing to activities considered immediate, necessary and sufficient to remove the cause of, or mitigate any actual or likely adverse effect of, any emergency (s330(2)). Immediacy, necessity and sufficiency are the key qualifying conditions governing the application of $\mathbf{s 3 3 0}$ of the Act. However the person or entity that is granted the emergency powers must have the capacity to do so. Section 330 (a)-(c) gives three sets of qualifications needed from persons or entities so that they will be able to carry out emergency activities under the Act. The practical application of these sections is that the proposed work must meet the emergency criteria before a bypass of the stipulated consent process can be activated, as long as the Consent Authority is advised within seven days that the emergency work was undertaken. In the event that the adverse effect and the emergency works continue, an application for resource consent must be made within 20 working days of any initial notification (s330B).

In spite of these provisions, the RMA became burdensome and a source of frustration during reconstruction works in the Manawatu floods of 2004 (Tonkin and Taylor, 2005). Much valuable time was lost trying to develop an understanding with the Regional Council about emergency actions that could cover all situations under the RMA, rather than requiring a formal process for each activity. Time wasting is highly probable under the RMA especially for significant national projects (Smith, 2009).

Public notification is unique to the RMA and allows community members in the immediate environment to work through all environmental impact issues before the local councils commit to a development project. However the stipulated notification and consultation procedures have further implication on post disaster recovery. At one extreme, strict implementation of the notification process may slow down recovery. Time is thus wasted going through submissions for and against a proposed development. In the event that a decision is not reached at the council level, the consent applications are transferred for hearing at the Environment Court. At the other 
extreme, there is the risk of non-participation by concerned parties which could negate the usefulness of public notification (Clark \& Newlove, 2001). Thus potentially harmful redevelopment projects may be wrongfully permitted.

\subsubsection{Dealing with Nationally Significant Projects}

Another dimension to the implementation of the RMA is the potential effect it could have on the rebuilding of critical infrastructure post disaster. $0.69 \%$ of the total consents declined in the 2005-2006 period were for major infrastructure projects that were in the national interest (IPENZ, 2008). Though the RMA provides for a fast track process for projects of national significance (s6, s141), there is no indication that critical reconstruction projects are adequately covered by this provision (McShane, 2008). Criteria such as the cost of projects, scale of projects, sphere of influence on the public are well established in the RMA; however there appears to be no specific criterion that could enable the classification of some reconstruction projects as being in the national interest. The absence of specific criteria that could fast-track critical reconstruction projects has the implication of delaying the projects beyond acceptable timeframes.

McShane (2008) suggests a cost-benefit assessment whereby the potential benefits of a proposed development would become additional criteria for classifying projects of national significance. Such assessments could be applied to reconstruction projects too so that public infrastructure projects and critical lifeline utility projects with demonstrated public/social benefits may be sped up through a bypass of normal consent processes.

With increased clarity on the projects that are nationally significant; Ministerial call-in provisions in the RMA (s141(B)) could be applied to significantly shorten the consenting process for such projects.

\section{Research Methodology}

The larger study on which this paper is based involved qualitative research methodology using multi-methods to determine the practical implication of implementing reconstruction arrangements under three legislative documents. However this paper presents one aspect of the study (involving an online survey) that captures opinions on the issues surrounding the implementation of the RMA for post-disaster reconstruction programmes. Four key themes are covered in the questionnaire in line with the study objective of identifying the improvements that could be made to the RMA so that it facilitates reconstruction works. The four themes include; the impact of the RMA on reconstruction, the RMA consent process, the RMA and its implementation, and the powers of Recovery Managers under the RMA.

The targeted participants for the survey included persons responsible for the implementation of three legislative documents within the local councils. However after phone calls to the councils, it was discovered that some of the councils had officers responsible for each of the three legislative documents, while a greater number of the councils had officers performing $\mathrm{dual} /$ multiple duties. Thus the research assumed that at least one-third of the 86 councils will produce three participants each $(\mathrm{N}=86)$, while the remaining two-third will produce two participants each respectively $(\mathrm{N}=114)$. Hence a total estimate of 200 responses.

There were four routes by which the survey was administered to the participants in order to increase the response rate. These were by direct administration of the survey to local councils, 
through the Coordinator of Regional Emergency Management Officers, selective distribution to interested persons and a general request for participation posted on 'Resilient Organisations' website. The total number of usable questionnaires after the online survey was closed was 80 . This corresponds to an overall response rate of $40 \%$. Table 1 gives a breakdown of the number of questionnaires received through each medium of questionnaire distribution.

The highest number of response came from the survey administered directly to the 86 local councils. The same set of questionnaires was administered to the selected participants irrespective of their background or inclinations. These participants completed parts of the questionnaire according to their understanding of the issues raised within the different parts of the survey questionnaire.

Table 1 - The distribution of online survey responses.

\begin{tabular}{|l|lcc}
\hline No. & \multicolumn{1}{|c}{ Medium of Distribution } & $\begin{array}{c}\text { No. of usable } \\
\text { Questionnaires }\end{array}$ & $\begin{array}{c}\text { Response rate of } \\
\text { expected 200 (\%) }\end{array}$ \\
\hline 1. & Local Councils & 57 & 28.5 \\
\hline 2. & $\begin{array}{l}\text { Coordinator, Regional Emergency Management } \\
\text { Officers }\end{array}$ & 19 & 9.5 \\
\hline 3. & Selected participants & 4 & 2 \\
\hline 4. & General notification (Resilient Organisation's website) & 0 & 0 \\
\hline
\end{tabular}

\section{Results and Discussion}

For the purpose of the study, the survey questions covered four themes that had emanated from preliminary reviews. The study results are clustered under the four themes and presented in the following subheadings. Some additional comments that were provided by the survey participants helped to further understand their responses and put the results in proper perspective. Some of such commentaries are presented in section 4.5.

\subsection{The RMA and its effectiveness in post-disaster reconstruction}

To determine the impact that the RMA will have on reconstruction projects, participants were presented with four statements. The research participants were required to indicate how well they agreed or disagreed with the four statements on a five point Likert scale. Their responses are expressed in percentages in Table 2. The opinion of participants on the first statement inquiring whether (or not) they believe the RMA will impede reconstruction works, is split with equal numbers agreeing or disagreeing with the statement. However, a slightly more prevalent opinion (above $45 \%$ as seen in Table 2) was observed on the second statement, which means that the RMA would have a negative effect on the efficiency of reconstruction activities after a disaster.

Table 2 - The RMA and reconstruction 


\begin{tabular}{|c|l|c|c|c|c|c|}
\hline & \multicolumn{1}{|c|}{ Statements } & SA & A & N & D & SD \\
\hline 1 & $\begin{array}{l}\text { The RMA will not impede the effective achievement } \\
\text { of reconstruction of built infrastructure. }\end{array}$ & $3.2 \%$ & $32.3 \%$ & $24.2 \%$ & $35.5 \%$ & $4.8 \%$ \\
\hline 2 & $\begin{array}{l}\text { The RMA will have a negative effect on efficiency } \\
\text { during reconstruction works. }\end{array}$ & $4.8 \%$ & $41.9 \%$ & $22.6 \%$ & $24.2 \%$ & $6.5 \%$ \\
\hline 3 & $\begin{array}{l}\text { The RMA will NOT become a regulatory burden on } \\
\text { disaster-affected property owners. }\end{array}$ & $1.6 \%$ & $33.9 \%$ & $16.1 \%$ & $46.8 \%$ & $1.6 \%$ \\
\hline 4 & $\begin{array}{l}\text { The RMA was a source of frustration in previous } \\
\text { disaster situations. }\end{array}$ & $1.6 \%$ & $9.7 \%$ & $69.4 \%$ & $11.3 \%$ & $8.1 \%$ \\
\hline
\end{tabular}

SA - Strongly Agree; A - Agree; N - Neutral/Unsure; D - Disagree; and SD - Strongly Disagree

On the third statement, a larger percentage (over 47\%) disagreed with the statement. This meant that the participants were of the opinion that the RMA will become a regulatory burden on disaster-affected property owners. Although the response to the fourth statement was inconclusive (69.4\% were unsure about whether the RMA was a source of frustration in previous disasters in New Zealand). It could be deduced from these results presented in Table 2 that the prevailing opinion is that the RMA may not permit the effective realisation of reconstruction objectives after disasters in New Zealand.

\subsection{The RMA Consent Process}

The objective of this section of the survey is to determine if research participants were supportive of the consent procedure outlined in the RMA and whether they consider public notification under the RMA as appropriate. There were three statements presented to participants for which they were required to indicate the level of their agreement or disagreement to the statements. A breakdown of the response is expressed in percentages on Table 3.

There was a prevailing pattern of response to the first statement on the effect of the RMA application process on reconstruction work. $58 \%$ of the research participants indicated that the application process for resource consent will slow down reconstruction programmes. This confirms earlier responses to statements made under theme 1. In a similar manner, more participants (38.7\%) are of the opinion that the requirements for consultation and public notification may have to be limited in scope to allow reconstruction works to be carried out unencumbered.

It would appear from the opinions expressed that participants recognise the importance of public consultations, but they also feel that a narrower scope will be more effective.

Table 3 - The RMA and consent processing

\begin{tabular}{|l|l|c|c|c|c|c|}
\hline \multicolumn{1}{|c|}{ Statements } & SA & A & N & D & SD \\
\hline 1 & $\begin{array}{l}\text { The application process for resource consent will NOT } \\
\text { slow down reconstruction programmes. }\end{array}$ & $6.5 \%$ & $16.1 \%$ & $19.4 \%$ & $53.2 \%$ & $4.8 \%$ \\
\hline 2 & The RMA places too much emphasis on consultation. & $4.8 \%$ & $19.4 \%$ & $35.5 \%$ & $33.9 \%$ & $6.5 \%$ \\
\hline
\end{tabular}




\begin{tabular}{|l|l|c|c|c|c|c|}
\hline 3 & $\begin{array}{l}\text { The consultation process needs NOT to be limited in } \\
\text { scope because of reconstruction demands. }\end{array}$ & $3.2 \%$ & $35.5 \%$ & $38.7 \%$ & $21.0 \%$ & $1.6 \%$ \\
\hline
\end{tabular}

SA - Strongly Agree; A - Agree; N - Neutral/Unsure; D - Disagree; and SD - Strongly Disagree

\subsection{Implementing the RMA}

Following on from the procedural issues related to the implementation of the RMA, this section has as its objective the determination of the problems experienced by local authorities during the implementation of RMA provisions. The direction of participants' opinions is presented in Table 4.

Table 4 presents a prevailing agreement with the two statements, with over $62 \%$ and $54 \%$ agreeing with statements 1 and 2 respectively. Participants therefore expressed the view that there could be conflicts between different tiers of government on the implementation of some provisions of the RMA. They also indicated that it is possible that the implementation of the RMA across territorial local authorities may result in jurisdictional conflicts.

Table 4 - Implementation of the RMA

\begin{tabular}{|l|l|c|c|c|c|c|}
\hline & \multicolumn{1}{|c|}{ Statements } & SA & A & N & D & SD \\
\hline 1 & $\begin{array}{l}\text { There is the possibility of conflict between the different } \\
\text { tiers of government concerning the implementation of } \\
\text { the RMA. }\end{array}$ & $8.2 \%$ & $54.1 \%$ & $23.0 \%$ & $11.5 \%$ & $3.3 \%$ \\
\hline 2 & $\begin{array}{l}\text { There could be jurisdictional conflicts between } \\
\text { councils and regions etc during reconstruction works } \\
\text { under the RMA. (N=62) }\end{array}$ & $4.8 \%$ & $50.0 \%$ & $19.4 \%$ & $21.0 \%$ & $4.8 \%$ \\
\hline
\end{tabular}

\subsection{Powers of Recovery Management under the RMA}

The last theme investigated by the survey is the opinion of research participants concerning the powers and responsibilities of Recovery Managers towards the coordination and implementation of reconstruction projects in New Zealand. Participants were to indicate whether they felt Recovery Managers should be allowed to veto any aspect of the RMA that could restrict the execution of reconstruction projects.

The prevailing opinion (42\%) was for Recovery Managers to be allowed to veto the RMA, where there was a clear need to do so. Whereas a comparatively lower percentage $(38.1 \%)$ of participants were either neutral or disagreed with this statement.

\subsection{General discussion}

The survey results show that participants agree that the RMA will impact reconstruction activities and programmes. For instance, the emphasis on public notification and wider consultation on the environmental impacts of proposed developments is likely to slow down the reconstruction of damaged physical assets. This signifies that more flexibility in the current resource consent process is desirable. 
Participants indicated that, while the RMA could be considered burdensome, it was also necessary to regulate reconstruction to avoid a recurrence of existing vulnerabilities. The RMA was commended by one participant as being crucial to risk and hazard reduction. However, there seems to be a need to improve processes around emergency work provisions to reduce the potential for the RMA to become an impediment to reconstruction activities. One participant suggests that there is a lot of inconsistency between different territorial local authorities on how emergency work provisions are implemented. Similar conclusions are made by some participants (identified here as P001 and P002) on how large scale reconstruction programmes could be facilitated through enabling provisions in the RMA.

Improvements to RMA... to better provide for emergency works, AND better training and information to support Councils using these provisions (there is currently a lot of inconsistency in how emergency works provisions under the RMA are implemented, for example). (P001)

There is a clear need to identify what can, and cannot, be done under 'emergency works'. This will negate the potential backlog of regulatory 'red tape' whilst still providing surety of maintaining acceptable standards. Bypassing the regulatory [provision] is a 'licence' to build substandard buildings. (P002)

The survey results give an indication that the powers to progress recovery activities by Recovery Managers would need to be enhanced. The prevailing opinion is that Recovery Managers or appointed Recovery Coordinators should have the capacity to veto certain requirements/provisions under the RMA to allow for reconstruction work to progress with little hindrance. Some caution is noted here since sub-standard works may create difficulties when the situation normalises.

Finally, the study observed that jurisdictional conflicts may arise in RMA implementation between local councils in New Zealand. For instance, a participant alluded to the presence of subtle differences exist between individual District Plans that could influence how the RMA is interpreted and implemented across different local councils. Such inconsistencies are potential problem areas that may have to be overcome so that they do not hinder the progress of reconstruction activities. Differential progress (and interpretation of standards) during recovery between local councils may not augur well for overall recovery efforts, particularly to individual house owners who may be frustrated by consenting processes in the post-disaster phase.

\section{Recommendations for improving the RMA}

Previous studies had alluded to the frustration experienced in previous recovery programmes largely because of procedural requirements and other provisions for wide consultation contained in the RMA. This issue was confirmed by research participants in the current study. The impacts to reconstruction programmes were in the form of delays and high consent costs. The study therefore recommends that the scale of consultation or public notification be limited in a manner that permits a speedy approval process under the RMA. Improvement to consent processes would help to tackle the expected spike in consent application for minor works in the aftermath of a disaster.

The study concludes that the inclusion of provisions within the RMA that will require greater consideration of recovery issues by local councils is necessary. Currently, subtle differences that 
are alluded to by research participants in the implementation of provisions within different councils are the result of grey areas in subsisting district plans in New Zealand. The study recommends harmonious recovery planning and management policies to be incorporated into regional and district plans, to enhance their quality in post-disaster management. Current emphasis on prevention/avoidance and mitigation of hazards could then be extended to the recovery phase of a disaster.

The study recommends a streamline of the process for determining projects of national significance within the RMA. Greater clarity is needed on projects that could be considered nationally significant in New Zealand. This will enable a bypass of stipulated procedures and ultimately avoid wasted time and costs. Within the current RMA, criteria such as the cost of a project, scale of the project, sphere of influence on the public etc. may be established; but most importantly there should be a specific criterion that identifies critical reconstruction projects following large-scale disasters as being nationally significant. These changes will be consistent with the provisions for immediacy, necessity and sufficiency contained in Section 330 of the Act.

Probably in similar circumstances the study recommends the appointment of a National Recovery Coordinator into the membership of an Environmental Protection Authority (EPA) or any Board of Inquiry on environmental issues. This permanent role will help facilitate the identification and consenting of nationally significant re-instatement projects especially after disasters.

\subsection{Wider Implications of the study}

As can be seen from this research, improvements are necessary to existing environmental management legislation to enable more effective reconstruction following a natural hazard event. The results have implications for the wider disaster community where there seems to be limited research on the impact of regulations on building rehabilitation or on how procedural barriers discourage physical development and rehabilitation (Burby et al., 2006; May, 2004). Much of what exists in housing and disaster management literature is anecdotal and suggests that there is a relationship between building/environmental regulations and rehabilitation work (Martin, 2005). Some of these anecdotes do not provide enough empirical data for further research and Schill (2005) suggests that the lack of empirical data makes it difficult to influence public policy. This paper has presented information that supports the thesis that some aspects of legislation may have to be reviewed to meet emergency management objectives

Burdensome regulations incorporate excessive rules and regulations and red tape statutory procedures that add unnecessarily to cost (Martin, 2005) and prevent rebuilding at the speed desired by communities and individual property owners (Listokin \& Harris, 2004). Bureaucracies are less supportive of the expediency that is desired in disaster response and recovery (Olshansky, 2005; Rosenthal \& Kouzmin, 1997). They derive their strength and weaknesses from a modus-operandi that is time consuming, the typologies are 'procedure-bound' and are unable to foster creativity, improvisation, and the adaptability needed in disaster situations (Harrald, 2006). May (2004) suggests three sources of regulatory process barriers (regulatory approvals, enforcement strategies and practices, and patchwork of administrative arrangements) which are in line with the barriers posed by environmental legislation in New Zealand.

Procedural issues could also arise from administrative conflicts in and among disaster agencies (Listokin \& Harris, 2004). For example rivalry between responding agencies are not foreign to 
emergency services and are an obstacle to effective emergency management (Granot, 1997; McEntire, 2002; E. L. Quarantelli, 1988). Rivalry may result from existing silos or from the absence of a coordinating agency. Hence a broad range of cooperative effort is needed for the success of post disaster reconstruction activities. Organisations must coalesce to plan for resource utilisation in the restoration of physical assets. Such coordination is central to multi-organisational response and recovery programmes (Comfort et al., 1999; McEntire, 2002). The question for disaster management to address is, how to achieve the required coordination of its activities? The position of this paper is that a good start point will be to embed the requirements for the coordination and interaction of all stakeholders in legislation and regulatory provisions. This will then feed into respective community recovery plans with policies and specific criteria for post-disaster situations.

A useful dimension to the problem associated with burdensome regulations is provided by Listokin and Hattis (2004). It is that regulatory procedures could become too rigid, forcing implementers to 'go by the book' even though flexibility may be warranted. This places implementers in a state of continuous fear of liability should things go wrong. Some latitude of control and discretion is often required to aid decision making as long as such decisions are pragmatic. Commenting on the rebuilding programme after the flooding incident in New Orleans, Stackhouse (2006 p.36) says 'removing democratic processes from the rebuilding process has the advantage of expediting decision making by allowing politically dangerous but practical outcomes'. Conclusions from this study affirm the need to enhance powers and responsibilities of appointed Recovery Managers, and suggest that greater freedom in decision making by key officials of recovery coordinating agencies could increase the speed of rebuilding programmes after significant disaster events.

From the foregoing treatise, it is evident that legislation and regulations pertaining to post-disaster reconstruction need to be made more responsive to reconstruction objectives. Speed is of essence in disaster reconstruction while pre-planning using enhanced legislation could help to improve the speed and quality of reconstruction delivery (Harrald, 2006).

\section{Conclusion}

This paper has explored improvements to environmental management legislation so that they facilitate the implementation of post disaster reconstruction activities. Specific reference was made to the RMA in New Zealand and the practical implications of implementing reconstruction under its legislative framework. The paper draws on the information gathered from industry practitioners and uses the responses to reach a conclusion that the RMA's procedural requirements could become constraining and burdensome to property owners who desire early recovery from a disaster event. There is a pressing need for improvements to legislation before a significant disaster occurs. This will make environmental management legislation robust enough to facilitate post disaster reconstruction projects.

\section{References}

ACTIONAID Nepal. (2004). Disaster management in Nepal: Analysis of laws and policies. Nepal. ACTIONAID, Nepal.

Angus, L. (2005). New Zealand's response to the 1994 Yokohama strategy and plan of action for a safer world. Paper presented at the World Conference of Disaster Reduction, KobeHyogo, Japan.

Becker, J., \& Saunders, W. (2007). Enhancing sustainability through pre-event recovery planning. Retrieved $13^{\text {th }}$ October, 2008 from http://qualityplanning.org.nz/pubs/ 
Becker, J., Saunders, W., Hopkins, L., Wright, K., \& Kerr, J. (2008). Pre-event recovery planning for land-use in New Zealand: An updated methodology (p. 39): Institute of Geological and Nuclear Sciences Limited.

Burby, R. J., Salvesen, D., \& Creed, M. (2006). Encouraging residential rehabilitation with building codes: New Jersey experience. Journal of the American Planning Association, 72(2), 183-196.

Chan, Y., Alagappan, K., Gandhi, A., Donovan, C., Tewari, M., \& Zaets, S. B. (2006). Disaster management following the Chi-Chi earthquake in Taiwan. Prehospital Disaster Medicine, 21(3), 196-202.

Clark, L., \& Newlove, F. (2001). Taking a closer look at public notices. Planning Quarterly. September.

Coghlan, A. (2004). Recovery management in Australia: A community-based approach. Paper presented at the NZ Recovery Symposium, Napier, New Zealand, 81-91.

Comerio, M. C. (2004). Public policy for reducing earthquake risks: A US perspective. Building Research and Information, 32(5), 403-413.

Comfort, L., Wisner, B., Cutter, S., Pulwarty, R., Hewitt, K., Oliver-Smith, A., Wiener, J., Fordham, M., Peacock, W., \& Krimgold, F. (1999). Reframing disaster policy: The global evolution of vulnerable communities. Environmental Hazards, 1, 39-44.

Cousins, T. (2004). A holistic framework for recovery: What happens when and works best. Paper presented at the NZ Recovery Symposium, Napier, New Zealand, 120-134.

EM-DAT. (2011). 2010 disasters in numbers. The OFDA/CRED International Disaster Database, 1-2. Retrieved from http://cred.be/sites/default/files/PressConference2010.pdf

Feast, J. (1995). Current planning and construction law: The practical consequences for rebuilding Wellington after the quake. Paper presented at the Wellington After the 'Quake: The Challenges of Rebuilding Cities Conference, Wellington, New Zealand, 161-169.

Gavidia, J., \& Crivellari, A. (2006). Legislation as vulnerability factor. Open House International, 31(1), 84-89.

Granot, H. (1997). Emergency inter-organizational relationships. Disaster Prevention and Management, 6(5), 305-312.

Harper, A. (2006). Legislative and case law relevant to the application of legislative emergency provisions. Ministry of Civil Defence and Emergency Management (pp. 44). Christchurch: Anthony Harper Lawyers.

Harrald, J. R. (2006). Agility and discipline: Critical success factors for disaster response. The ANNALS of the American Academy of Political and Social Science, 604(1), 256-272.

Hendrikx, J. (2006). Preliminary analysis of the June 122006 Canterbury snow storm. Orion New Zealand Limited (pp. 26): National Institute for Water and Atmospheric Research Ltd.

Hopkins, D. C, Lanigan, A. G., \& Shephard, R. B. (1999). The great Wellington quake: A challenge to the construction industry. New Zealand: Earthquake Commission.

IPENZ. (2008). Review of the Resource Management Act. The Institution of Professional Engineers New Zealand (IPENZ). 
Jigyasu, R. (2004). Sustainable post-disaster reconstruction through integrated risk management. Paper presented at the Second International Conference, Centre for Disaster Management, Coventry University. U.K.

Kennedy, J., Ashmore, J., Babister, E., \& Kelman, I. (2008). The meaning of 'build back better': Evidence from post-Tsunami Aceh and Sri Lanka. Journal of Contingencies and Crisis Management 16(1), 24-36.

Kouzmin, A., Jarman, A. M. G., \& Rosenthal, U. (1995). Inter-organizational policy processes in disaster management. Disaster Prevention and Management, 4(2), 20-37.

Le Masurier, J., Rotimi, J. O. B., \& Wilkinson, S. (2006). A Comparison between routine construction and post-disaster reconstruction with case studies from New Zealand. Paper presented at the 22nd ARCOM Conference on Current Advances in Construction Management Research, Birmingham, U.K.

Listokin, D., \& Hattis, D. (2004). Building Codes and housing. Paper presented at the Workshop on Regulatory Barriers to Affordable Housing, U.S. Department of Housing and Urban Development Washington, D.C.

Martin, C. (2005). Response to "Building Codes and Housing” by David Listokin and David B. Hattis. Cityscape: A Journal of Policy Development and Research, 8(1), 253-259.

May, P. J. (2004). Regulatory implementation: Examining barriers from regulatory processes. Paper presented at the Workshop on Regulatory Barriers to Affordable Housing, US Department of Housing and Urban Development Washington, D.C.

MCDEM. (n.d.). Get ready get thru. Ministry of Civil Defence and Emergency Management. Retrieved from http://www.mcdem.govt.nz/memwebsite.nsf/wpg_URL/For-the-CDEMSector-Publications-Index?OpenDocument.

McDonald, C. (2004). The promise of destruction. The Australian Journal of Emergency Management, 19 (4), 51-55.

McEntire, D. A. (2002). Coordinating multi-organisational responses to disaster: Lesson from the March 28, 2000, Fort Worth tonardo. Disaster Prevention and Management, 11(5), 369-379.

McShane, O. (2003). Do councils meet their deadline? Centre for Resource Management Studies (p. 13). Northland, New Zealand.

McShane, O. (2008). RMA - Issues for early reform: Part I. Centre for Resource Management Studies, Northland, New Zealand.

Meese, E., Butler, S. M., \& Holmes, K. R. (2005). From tragedy to triumph: Principled solutions to rebuilding lives and communities. Heritage Special Report SR-05, Retrieved $20^{\text {th }}$ October, 2006, from http://www.heritage.org/research/Regulation/

Ministry for Culture and Heritage. (2009). New Zealand disasters timeline. Retrieved 13 June, 2009 from http://www.nzhistory.net.nz/culture/new-zealand-disasters/timeline

Ministry for Environment. (2006). Your guide to the Resource Management Act. ME 766, Ministry for Environment. 
Ministry for Environment. (2008). A review of council RMA resource consent processing performance: Round two. ME 845, Ministry for Environment.

Ministry for Environment. (2009). Resource Management Act: Two-yearly survey of local authorities 2007/2008. ME 938, 937, Ministry for Environment.

Mitchell, J. K. (2006). The primacy of partnership: Scoping a new national disaster recovery policy. The ANNALS of the American Academy of Political and Social Science, 604(1), 228-255.

Nigg, J. M., Barnshaw, J., \& Torres, M. R. (2006). Hurricane Katrina and the flooding of New Orleans: Emergent Issues in sheltering and temporary housing. The ANNALS of the American Academy of Political and Social Science, 604(1), 113-128.

Olshansky, R. B. (2005). How do communities recover from disaster? A review of current knowledge and an agenda for future research. Paper presented at the 46th Annual Conference of the Association of Collegiate Schools of Planning, Kansas City.

Page, I. (2005). The Building Act and land hazards planning. In G. Beattie (Ed). E387 (pp. 1-17). Porirua: BRANZ Limited.

Quarantelli, E. L. (1988). Disaster crisis management: A summary of research findings. Journal of Management Studies, 25(4), 373-385.

Quarantelli, E. L. (2006). The disaster recovery process: What we know and do not know from research. Retrieved $3^{\text {rd }}$ October 2006, from http://www.udel.edu/

Rosenthal, U., \& Kouzmin, A. (1997). Crises and crisis management: Toward comprehensive government decision making. Journal of Public Administration Research and Theory, 7(2), 277-304.

Schill, M. H. (2005). Regulations and housing development: What we know. Cityscape: A Journal of Policy Development and Research, 8(1), 5-19.

Schneider, S. K. (1995). Flirting with disaster: Public management in crisis situations. M.E. Sharpe.

Shaw, R., Gupta, M., \& Sarma, A. (2003). Community Recovery and its Sustainability: Lessons from Gujarat earthquake of India. The Australian Journal of Emergency Management, 18(2), 28-34.

Skelton, P., \& Memon, A. (2002). Adopting sustainability as an overaching environmental policy: A review of section 5 of the RMA. Resource Management Journal, X(1), 1-10.

Smith, N. (2009). First reading of the RMA Reform Bill. Retrieved $2^{\text {nd }}$ March 2009, from http://www.beehive.govt.nz/speech/speech+first+reading+rma

Smith, W., \& Dowell, J. (2000). A case study of co-ordinative decision-making in disaster management. Ergonomics, 43(8), 1153-1166.

Spence, R. (2004). Risk and regulation: Can improved government action reduce the impacts of natural disasters? Building Research and Information, 32(5), 391-402.

Stackhouse, A. (2006). Where to begin: A framework for rebuilding New Orleans. [Melissa Vanlandingham]. Policy Matters, 3(2), 34-39. 
Tonkin and Taylor. (2005). Matata debris flows hazard and risk investigations (Regulatory Review). Report prepared for Whakatane District Council, New Zealand.

Ye, Y. (2002). Chinese experience with post-disaster reconstruction. Paper presented at the First International Conference on Improving Post-Disaster Reconstruction in Developing Countries. Universite de Montreal, Canada. 23-25 May. 